\title{
Congruent phylogeographical patterns of eight tree species in Atlantic Central Africa provide insights into the past dynamics of forest cover
}

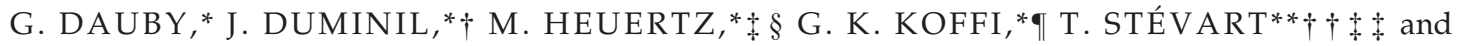 \\ O. J. HARDY* \\ ${ }^{*}$ Faculté des Sciences, Evolutionary Biology and Ecology, Université Libre de Bruxelles, CP160/12, 50 Av. F. Roosevelt, 1050 \\ Brussels, Belgium, $\uparrow$ Sub-Regional Office for Central Africa, Bioversity International, Forest Genetic Resources Programme, P.O. \\ Box 2008 Messa, Yaoundé, Cameroon, †Forest Ecology and Genetics, INIA Forest Research Centre, Ctra. A Coruña km 7.5, \\ 28040 Madrid, Spain, §Department of Biology, Unit Ecology and Evolution, Université de Fribourg, Chemin du Musée 10, 1700 \\ Fribourg, Switzerland, ๆUFR-Sciences de la Nature, Université Nangui Abrogoua, 02 BP 801, Abidjan, Ivory Coast, ${ }^{* *}$ Africa \\ and Madagascar Department, Missouri Botanical Garden, PO Box 299, St. Louis, MO, 63166-0299, USA, ††Herbarium et \\ Bibliothèque de Botanique africaine, Université Libre de Bruxelles, CP 169, 50 Av. F. Roosevelt, 1050 Brussels, Belgium, \\ $\$$ National Botanic Garden of Belgium, Domein van Bouchout, Nieuwelaan 38, B-1860 Meise, Belgium
}

\begin{abstract}
Cycles of Quaternary climatic change are assumed to be major drivers of African rainforest dynamics and evolution. However, most hypotheses on past vegetation dynamics relied on palaeobotanical records, an approach lacking spatial resolution, and on current patterns of species diversity and endemism, an approach confounding history and environmental determinism. In this context, a comparative phylogeographical study of rainforest species represents a complementary approach because Pleistocene climatic fluctuations may have left interpretable signatures in the patterns of genetic diversity within species. Using 1274 plastid DNA sequences from eight tree species (Afrostyrax kamerunensis, A. lepidophyllus, Erythrophleum suaveolens, Greenwayodendron suaveolens, Milicia excelsa, Santiria trimera, Scorodophloeus zenkeri and Symphonia globulifera) sampled in 50 populations of Atlantic Central Africa (ACA), we averaged divergence across species to produce the first map of the region synthesizing genetic distinctiveness and standardized divergence within and among localities. Significant congruence in divergence was detected mostly among five of the eight species and was stronger in the northern ACA. This pattern is compatible with a scenario of past forest fragmentation and recolonization whereby forests from eastern Cameroon and northeastern Gabon would have been more affected by past climatic change than those of western Cameroon (where one or more refugia would have occurred). By contrast, southern ACA (Gabon) displayed low congruence among species that may reflect less drastic past forest fragmentation or a more complex history of vegetation changes. Finally, we also highlight the potential impact of current environmental barriers on spatial genetic structures.
\end{abstract}

Keywords: Cameroon, Gabon, Lower Guinea, plastid DNA, refugia, tropical rainforest trees

\section{Introduction}

Geographic variation and global levels of species biodiversity in tropical forest ecosystems have often been

Correspondence: Dauby Gilles, Fax: +32 2650 4514;

E-mail: gildauby@gmail.com explained by historical factors, that is, differences in the timing and order of (re)colonization and variation in the level of diversification (Ricklefs 2004; Dexter et al. 2012). For example, the Quaternary climatic fluctuations (alternating drier/cooler and wetter/warmer periods) have long been considered as a driver of successive fragmentation and extension of tropical forest cover 
(e.g. Bonnefille 2007). The dynamics of forest extent may have left signatures in contemporary patterns of species diversity and endemism through enhanced allopatric speciation rates (Haffer 1969; Mayr \& O'Hara 1986) and/or through decreased extinction rates because of forest persistence in climatically stable refugia (e.g. Fjeldså \& Lovett 1997).

For Amazonian forests, the refugia hypothesis has been questioned (Knapp \& Mallet 2003) mainly because palaeoclimatic data do not clearly support forest fragmentation (Bush \& Oliveira 2006), and dated molecular phylogenies and palaeontological records suggest that most Amazonian species appeared before the Quaternary (Hoorn et al. 2011). Nonetheless, Dexter et al. (2012) showed that historical processes may still have a profound impact on tree community assembly and turnover at a regional scale. For the Central African forests, the refugia hypothesis has been widely embraced (Plana 2004). This interpretation is supported by palaeovegetation evidence (Bonnefille 2007), which, however, lacks sufficient spatial and temporal resolution. To which extent local composition of fossil pollen can be extrapolated to the regional level remains a difficult question (Lebamba et al. 2009).

As an alternative to palaeobotanical evidence, endemism and biodiversity patterns in Central Africa have been used for the reconstruction of forest refugia during the Quaternary (Maley 1996; Robbrecht 1996; Sosef 1996; Leal 2004). Several refugia have been proposed based on biogeographical data (mostly on birds and angiosperms, e.g. Maley 1987; Hamilton \& Taylor 1991). Many of them are located in Atlantic Central Africa (ACA, including Gabon, Cameroon, Equatorial Guinea and Republic of Congo), which constitutes the largest part of the Lower Guinea phytogeographical region, an area with very high levels of species diversity and endemism (Linder et al. 2012). However, inferring past forest refugia from the patterns of species endemism and biodiversity may be misleading because these patterns could also be shaped by contemporary environmental gradients (Fjeldså \& Lovett 1997; Droissart 2009). Hence, the impact of past climatic fluctuations on forest dynamics remains largely unknown and debated. In addition, as most of the diversification events responsible for the current species endemism probably predate the Pleistocene (Plana et al. 2004), Pleistocene climatic fluctuations may have left more interpretable signatures in the patterns of genetic diversity at the intraspecific level.

Comparative phylogeography is a powerful tool for inferring the impact of past and present-day barriers to gene flow (Avise 1992; Taberlet et al. 1998). Based on plastid DNA markers, this approach has been efficient for retracing the history of species range fragmentation and colonization in temperate biomes (e.g. Taberlet et al. 1998; Petit et al. 2003; Schönswetter et al. 2005). Past fragmentation of the forest cover is expected to leave the following signatures in the spatial patterns of genetic diversity. First, the geographical isolation of refugia would increase the impact of genetic drift leading to a genetic differentiation among refugia, and an accumulation of endemic intraspecific lineages in each refugium. Second, the recolonization from refugia would lead to lower diversity of haplotypes outside refugia due to repeated founder effects, except possibly in areas recolonized from different refugia (Hewitt 2000; Petit et al. 2003). Third, the spatial distribution of genetic diversity should be congruent among species if they share a common demographical history (Bermingham \& Moritz 1998; Zink 2002; Petit et al. 2003).

A first phylogeographical study did not reveal any shared genetic structure pattern at plastid DNA markers among fourteen tree taxa in Atlantic Central Africa; however, the study was limited by low sampling intensity within each taxon, and more intensive sampling of four of the species suggested the existence of a northsouth genetic divide in the region (Heuertz et al. 2014). A recent review mostly based on microsatellite data reported some spatial congruence among African tree species in the limits between parapatric gene pools, but not in the pattern of allelic endemism (Hardy et al. 2013), although the homoplasy and high mutation rates of microsatellite markers may have erased such a pattern.

Here, we used plastid DNA (pDNA) sequences from eight tree species, displaying various dispersal syndromes and habitat preferences (Table 1), but all typical of terra firme moist/wet Central African forests. pDNA is well suited for inferring past population dynamics through seed dispersal because it is generally maternally inherited in angiosperms (Petit et al. 2003). We predict the following genetic diversity patterns for multiple species according to two distinct forest dynamics scenarios during the Pleistocene in ACA.

1 Large parts of ACA were periodically composed of unsuitable habitats for forest species (e.g. savannahs); hence, the latter survived in a limited number of relatively large forest refugia (e.g. upland areas or major river drainages). Under this scenario, we would expect congruent and spatially structured patterns of genetic diversity across forest species. In particular, we would expect past refugia to harbour both congruent high levels of genetic distinctiveness among populations and high levels of population genetic diversity. By contrast, areas with congruent low levels of genetic distinctiveness and population haplotype diversity would probably indicate recolonized 
Table 1 Ecological and chorological characteristics of the eight studied African tree species

\begin{tabular}{|c|c|c|c|}
\hline Species (Family) & Autecology & $\begin{array}{l}\text { Seed dispersal } \\
\text { syndrome/vectors }\end{array}$ & Distribution* \\
\hline $\begin{array}{l}\text { Afrostyrax kamerunensis } \\
\text { Perkins \& Gilg (Huaceae) }\end{array}$ & $\begin{array}{l}\text { Small tree. Locally abundant. } \\
\text { Shade-tolerant. }\end{array}$ & $\begin{array}{l}\text { Unknown } \\
\text { (indehiscent fruit). }\end{array}$ & Disjunct. LG and C. \\
\hline $\begin{array}{l}\text { Afrostyrax lepidophyllus } \\
\text { Mildbr. (Huaceae) }\end{array}$ & $\begin{array}{l}\text { Large tree. Locally abundant. } \\
\text { Very rare/absent } \\
\text { at elevation }<200 \mathrm{~m} \text {. Shade-tolerant. }\end{array}$ & $\begin{array}{l}\text { Unknown } \\
\text { (indehiscent fruit). }\end{array}$ & Widespread. GC. \\
\hline $\begin{array}{l}\text { Erythrophleum suaveolens } \\
\text { (Guill. \& Perr.) } \\
\text { Brenan (Fabaceae) }\end{array}$ & $\begin{array}{l}\text { Large tree. Locally abundant in } \\
\text { semi-deciduous } \\
\text { forests, rare in evergreen forests. } \\
\text { Light-demanding. }\end{array}$ & Ballochorous $^{\dagger}$ & Widespread. GC. \\
\hline $\begin{array}{l}\text { Milicia excelsa (Welw.) } \\
\text { C.C.Berg (Moraceae) }\end{array}$ & $\begin{array}{l}\text { Large tree. Locally abundant in } \\
\text { semi-deciduous forests, } \\
\text { rare in evergreen forests. Light-demanding. }\end{array}$ & Zoochorous/bats & $\begin{array}{l}\text { Widespread. } \\
\text { GC and periphery. }\end{array}$ \\
\hline $\begin{array}{l}\text { Greenwayodendron suaveolens } \\
\text { (Engl. E Diels) Verdc. } \\
\text { subsp. suaveolens var. } \\
\text { suaveolens (Annonaceae) }\end{array}$ & $\begin{array}{l}\text { Medium-sized tree, abundant and } \\
\text { common in mature } \\
\text { rainforests. Shade-tolerant. }\end{array}$ & $\begin{array}{l}\text { Zoochorous/birds, } \\
\text { elephant, primates. }\end{array}$ & Widespread. GC. \\
\hline $\begin{array}{l}\text { Santiria trimera (Oliv.) } \\
\text { Aubrév. (Burseraceae) }\end{array}$ & $\begin{array}{l}\text { Large tree, locally abundant. } \\
\text { Shade-tolerant. }\end{array}$ & $\begin{array}{l}\text { Zoochorous/birds, } \\
\text { primates. }\end{array}$ & Widespread. GC. \\
\hline $\begin{array}{l}\text { Scorodophloeus zenkeri } \\
\text { Harms (Fabaceae) }\end{array}$ & $\begin{array}{l}\text { Large tree, dominant. Gregarious species. } \\
\text { Very rare at elevation }<200 \mathrm{~m} \text {. Shade-tolerant. }\end{array}$ & Ballochorous. & Widespread/disjunct. GC. \\
\hline $\begin{array}{l}\text { Symphonia globulifera L.f. } \\
\text { (Clusiaceae) }\end{array}$ & $\begin{array}{l}\text { Large tree, wide ecological amplitude } \\
\text { in evergreen forests. Shade-tolerant. }\end{array}$ & $\begin{array}{l}\text { Zoochorous/hornbills, } \\
\text { primates, duikers. }\end{array}$ & $\begin{array}{l}\text { Widespread. } \\
\text { GC in Africa } \\
\text { and Neotropics. }\end{array}$ \\
\hline
\end{tabular}

*LG, Lower Guinea phytogeographical domain; C, Congolian phytogeographical domain; GC, Guineo-Congolian phytogeographical region (LG+C+ Upper Guinea phytogeographical domain).

†Field observations indicate that seeds might be swallowed by gorillas and released without damage (C-A Petre, personal communication.)

areas. Zones of admixture could also emerge and would correspond to the confluence of recolonization routes from distinct refugia (Petit et al. 2003).

2 Past climatic changes uniformly affected forest cover across the whole ACA. Two variants of this scenario can be proposed: (a) forest species' populations have been impacted and may have persisted in multiple azonal forest habitats (e.g. gallery forests) depending on their ecological characteristics. Contrarily to the first scenario, current forest populations would originate from numerous microrefugia widely distributed and interconnected. (b) Past climatic changes have not affected strongly forest cover, and forest species' populations remained relatively stable. In both cases, migration would have allowed substantial gene flow among populations, limiting the impact of genetic drift. In addition, impact of climatic change would have been homogeneous across regions. We would therefore expect incongruent patterns of genetic diversity among forest species.

Hence, congruence of genetic diversity of forest species would suggest shared forest refugia for tree species in ACA and support scenario 1 while incongruent patterns could be explained by scenarios $2 a$ and $2 b$. In the following, we evaluated the spatial congruence of population genetic diversity and distinctiveness patterns among eight tree species, relying on an extensive data set of pDNA sequences.

\section{Materials and methods}

\section{Species studied and sampling}

Table 1 summarizes chorological data and ecological traits for the eight studied tree species. Six of them are able to regenerate under the canopy and can thus be considered as shade-tolerant species. Erythrophleum suaveolens and Milicia excelsa are nonpioneer lightdemanding species frequent in semi-deciduous forests although they occur in mature and evergreen rainforests. The eight species have overlapping ranges in west Gabon, but not all species occur in each sampled region (Fig. 1). These species were chosen because they are typical of terra firme rainforests and thus should be appropriate for tracking the variation in forest cover 


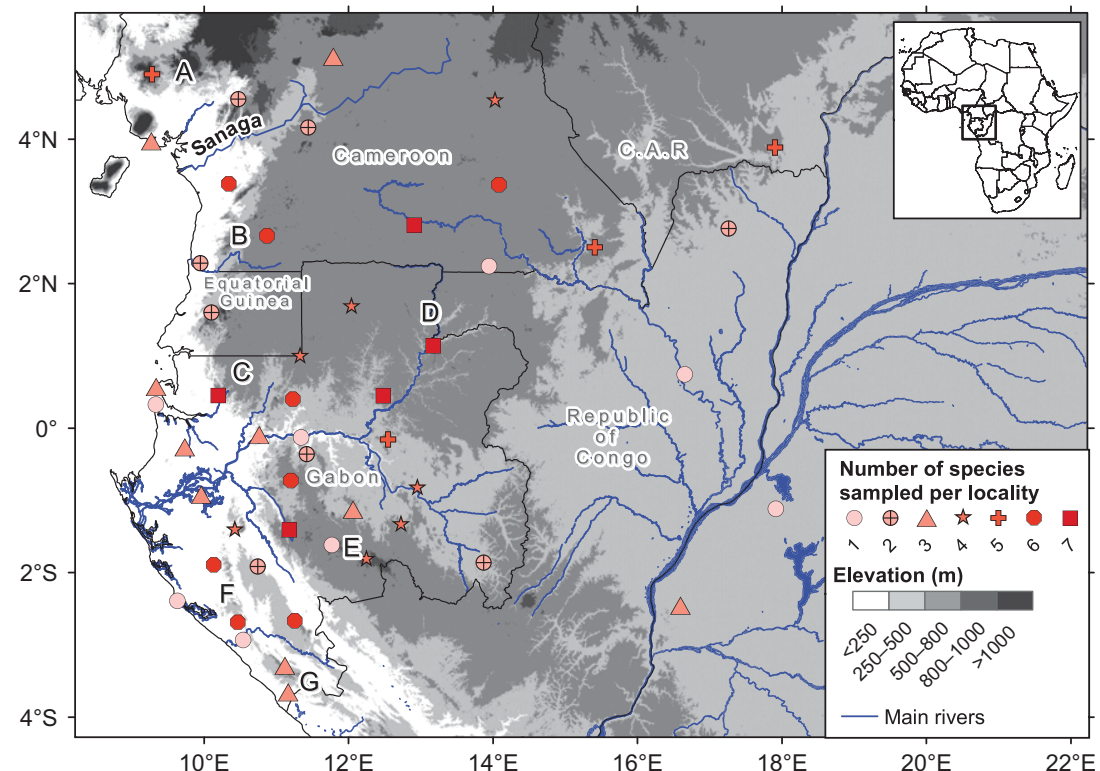

Fig. 1 Sampled localities, main rivers and elevation patterns in Atlantic Central Africa. Numbers refer to approximate localization of putative refugia proposed in the literature and inferred from patterns of biodiversity and endemism. (A) Cameroonian volcanic line, (B) Ngovayang massif, (C) Monts de Cristal, (D) Monts de Belinga, (E) Massif du Chaillu, (F) Monts Doudou, (G) Mayombe. during past climatic fluctuations. The phylogeographical patterns of three species are characterized for the first time in the present study: Afrostyrax kamerunensis, Afrostyrax lepidophyllus and Scorodophloeus zenkeri. The phylogeographical patterns of the other five species have been characterized in previous studies: Greenwayodendron suaveolens subsp. suaveolens var. suaveolens by Dauby et al. (2010), below noted as G. suaveolens; Erythrophleum suaveolens by Duminil et al. (2010); Santiria trimera by Koffi et al. (2011), though we considered here only the widespread morphotype with stilt roots and small leaflets (Koffi et al. 2010); Milicia excelsa by Daïnou et al. (2010); and Symphonia globulifera by Budde et al. (2013) for the locus $p s b A-t r n H$, though we here use the locus trnC-pet $1 \mathrm{Nr}$ as in Heuertz et al. (2014). For two of the species, E. suaveolens and G. suaveolens, new sequences and populations have been added to the existing data sets.

In total, 50 populations were sampled across Atlantic Central Africa (Fig. 1, Table S1, Supporting information). A population is here defined as a set of individuals separated by $<20 \mathrm{~km}$ (sample sizes ranged from 1 to25). For diversity analysis, only populations with at least three sampled individuals were retained. To compare patterns among species, we considered populations from different species occurring in the same locality. In the following, the term 'population' is used for a group of sampled individuals belonging to one species and the term 'locality' for a group of at least two populations of different species sampled nearby. Overall, there were 42 localities among which 34 with at least three sampled species (Fig. 1, Table S1, Supporting information). For each species, pieces of leaves or cambium were collected in the field and immediately dried in silica gel. The geographical position was determined using a GPS, and the identification was assured in the field. When the identification was doubtful, a herbarium voucher was collected and compared to collections deposited in institutions with holdings from Central Africa (National Herbarium of the Netherlands, Wageningen branch (WAG), the National Herbarium of Gabon (LBV) and the Herbarium of the Université Libre de Bruxelles (BRLU), acronyms according to Index Herbariorum, http:/ / sweetgum.nybg.org/ih/).

\section{DNA extraction and amplification}

Total DNA was isolated from ca. $10 \mathrm{mg}$ of dried plant material with the NucleoSpin ${ }^{\circledR}$ plant kit from Macherey-Nagel or from ca. $20 \mathrm{mg}$ of dried plant material following a CTAB protocol (Doyle \& Doyle 1987). Polymerase chain reactions (PCRs) of pDNA regions were carried out in a Biometra TProfessional thermocycler using universal primers. We tested several pDNA regions for polymorphism (Shaw et al. 2005). For all species but $S$. trimera, the $\operatorname{trnC}$-petN1R intergenic spacer was considered because it displayed relatively high levels of polymorphism (sequence lengths varied between 726 and 996 base pairs). For S. trimera, two pDNA regions ( $r p l 26-i n f A-r p s 8$ and part of the $r b c L$ gene for a total sequence length of 1178 base pairs) were retained (Koffi et al. 2011). For M. excelsa, we also sequenced the $p s b A$-trnH intergenic spacer in addition to the $\operatorname{trnC}$ petN1R intergenic spacer (Daïnou et al. 2010), totalizing a sequence length of 1419 base pairs. The PCRs were performed in a reaction volume of $25 \mu \mathrm{L}$ containing 
$2.5 \mathrm{~mm} \mathrm{MgCl2}, 0.2 \mathrm{~mm}$ of each dNTP, $0.1 \mathrm{~mm}$ of both primers, 0.625 units of Taq polymerase (Quiagen, Venlo, the Netherlands) and $1 \mu \mathrm{L}$ of DNA (diluted or not). Amplification conditions were $94{ }^{\circ} \mathrm{C}$ for $3 \mathrm{~min}$; 35 cycles at $94{ }^{\circ} \mathrm{C}$ for $30 \mathrm{~s}, 50{ }^{\circ} \mathrm{C}$ for $30 \mathrm{~s}$ and $72{ }^{\circ} \mathrm{C}$ for $1 \mathrm{~min} 20 \mathrm{~s}$; and final extension at $72{ }^{\circ} \mathrm{C}$ for $7 \mathrm{~min}$. Sequencing was carried out using BigDye v.3.1 chemistry (Applied Biosystems, Lennik, Belgium). Alignment and base calling of sequences were performed with the Codoncode Aligner program (CodonCode Corp. Dedham, Massachusetts, USA). Forward and reverse sequences were first aligned for each individual. Then, multiple alignments were processed within each species (the two species of Afrostyrax were aligned together to verify whether haplotypes were shared between the two sister species).

\section{Phylogenetic networks and mapping of haplotypes}

For each species, we constructed a phylogenetic network among haplotypes using a maximum parsimony method based on a median-joining algorithm as implemented in the software NETWORK 4.6 (Bandelt et al. 1999). We considered all kinds of polymorphisms except simple sequence repeats (SSR), including indels and inversions, which we coded as single mutation events. We mapped the distribution of haplotypes by linking all populations that host a given haplotype to the centroid of this haplotype using the software GEOPHYLOBUILDER 1.0 (Kidd \& Liu 2008). This representation is straightforward for visualizing the distribution of spatially structured haplotypes because there will be little or no overlap in the centroid network.

\section{Diversity and differentiation statistics}

We computed unordered and ordered diversity sensu Pons \& Petit (1996), estimating, respectively, the probability that two individuals carry distinct haplotypes $(h)$ and the mean genetic distance between the haplotypes of two individuals $(v)$. We used the minimal number of mutational steps between haplotypes as a measure of genetic distance, considering single-nucleotide, insertion-deletion and inversion polymorphisms. Genetic distances were then standardized by the mean genetic distance between haplotypes (weighted by haplotypes frequencies) to obtain comparable $v$ values among species (i.e. values independent from the overall level of sequence polymorphism; Pons \& Petit 1996). For each species, these diversity indices were computed for each population $i\left(h_{i}\right.$ and $v_{i}$, computed as the mean pairwise $h$ and $v$ between individuals from $i$ ) and for each pair of populations $i$ and $j\left(h_{i j}\right.$ and $v_{i j}$, computed as the mean pairwise $h$ and $v$ between individuals from $i$ and $j$ ). The $h_{i}$ and $v_{i}$ values were then averaged over populations, giving $h s$ and $v s$, and the $h_{i j}$ and $v_{i j}$ values were averaged over all population pairs, giving $h t$ and $v t$ (Pons \& Petit 1996).

Global differentiation between populations was quantified by $G_{\mathrm{ST}}(1-h s / h t)$ and $N_{\mathrm{ST}}(1-v s / v t)$. A phylogeographical signal occurs when distinct haplotypes within populations are significantly more related than distinct haplotypes from different populations, in which case $N_{\mathrm{ST}}>G_{\mathrm{ST}}$. To test whether $N_{\mathrm{ST}}$ was significantly higher than $G_{S T}$, a randomization procedure permuting haplotype assignation in the matrix of genetic distances among haplotypes was performed and repeated 10000 times, generating a distribution of permuted $N_{\mathrm{ST}}$ values. The proportion of permuted $N_{\mathrm{ST}}$ values higher than the observed $N_{\text {ST }}$ provided a $P$-value (unilateral test). The software SPAGEDI 1.4 (Hardy \& Vekemans 2002) was used to perform the test.

Pairwise differentiation between populations ( $i$ and $j$ ) was quantified by $G_{\mathrm{ST} i j}=1-\left(h_{i}+h_{j}\right) /\left(2 h_{i j}\right)$ and $N_{\mathrm{ST} i j}=1-\left(v_{i}+v_{j}\right) /\left(2 v_{i j}\right)$, as well as by $v_{i j}$ (proportional to the average number of mutations between two individuals drawn from populations $i$ and $j$ ). $G_{\text {ST } i j}$ and $N_{\mathrm{ST} i j}$ are complementary because while $G_{\mathrm{ST} i j}$ is based only on haplotype frequencies, $N_{\mathrm{ST} i j}$ also integrates haplotype evolution and better reflects deep differentiation. $N_{\mathrm{ST} i j}$ and $v_{i j}$ are complementary because while $N_{\mathrm{ST} i j}$ is affected by genetic drift within populations, this is not the case of $v_{i j}$. The $N_{\text {ST } i j}$ and $G_{\text {ST } i j}$ matrices were obtained with the software SPAGEDI 1.4 (Hardy \& Vekemans 2002). The $v_{i j}$ matrix was obtained in the R statistical software (R Development Core Team 2011) using the Picante package (Kembel et al. 2010).

\section{Standardized divergence among populations and localities and distinctiveness of populations and localities}

We measured the level of distinctiveness of each population and locality with respect to the other ones as follows. First, for each species, pairwise differentiation measures between populations $\left(N_{\mathrm{ST} i j}\right.$ or $\left.v_{i j}\right)$ were regressed on the $\ln$ (spatial distance) using a linear model. Second, we extracted and standardized the residual values of this linear regression (dividing them by their standard deviation). Thus, for each species $(k)$ and each pair of populations ( $i$ and $j$ ), we obtained pairwise standardized divergence values among populations $S_{k i j}$ or $S^{\prime}{ }_{k i j}$ using pairwise $N_{\mathrm{ST} i j}$ or $v_{i j}$, respectively. Third, we averaged these standardized divergence values across species for each pair of localities. We finally obtained one matrix of multiple-species pairwise comparisons between localities of divergence $\left(S_{. i j}\right.$ or $\left.S^{\prime}{ }_{i j}\right)$, indicating whether divergence is above (positive values) 
or below average (negative values), after accounting for spatial distance. The genetic distinctiveness of a focal population $i$ (for a species, $S_{k i}$. or $S_{k i}^{\prime}$ ) or locality $i$ (for multiple species, $S_{. i .}$ or $S^{\prime}{ }_{i .}$ ) was then estimated by the mean of standardized residuals that involved this given population or locality. Positive and negative values can thus be interpreted as a level of genetic distinctiveness, respectively, above and below average.

\section{Congruence of phylogeographical patterns}

Congruence among species was evaluated (i) using matrices of pairwise standardized divergence among populations $\left(S_{k i j}\right.$ or $\left.S^{\prime}{ }_{k i j}\right)$ and (ii) comparing population diversity values $\left(h_{i}\right.$ and $\left.v_{i}\right)$ within each locality.

Congruence of divergence patterns among species. To test whether species display congruent patterns, we used the matrices of $S_{k i j}$ or $S_{k i j}^{\prime}$ values among localities that shared at least two species sampled. We compared the average variance of $S_{k i j}$ or $S^{\prime}{ }_{k i j}$ across species within pairs of localities, $V p_{w}$, to the overall variance, $V p_{t}$. If there is a global congruence among divergence patterns, we expect $V p_{w}<V p_{t}$. Pairwise divergence values between populations being nonindependent, classical ANOVA tests cannot be applied. Therefore, to test whether $V p_{w}<V p_{t}$, we relied on a nonparametric test, generating artificial $S_{k i j}$ or $S_{k i j}^{\prime}$ matrices conforming to the null hypothesis (Ho) that $V p_{w}=V p_{t}$ by randomly permuting the populations, independently for each species. We performed 999 permutations, providing a frequency distribution of $V p_{w}$ under Ho, and estimated a $P$-value from the proportion of the distribution lower than or equal to the observed value. We also evaluated the congruence for each pair of species using Mantel tests between $S_{k i j}$ and $S_{k i j}^{\prime}$ matrices. For a visual inspection of how congruence varied geographically, we mapped the distinctiveness values of each species having either above- or below-average $S_{k i}$. or $S_{k i}^{\prime}$. values for each locality.

Congruence of population diversity among species. We evaluated the congruence of haplotype diversity by comparing the average variance across species of $h_{i}$ and $v_{i}$ values within localities, $V l_{w}$, to the overall variance $V l_{t}$. If congruence occurs, we expect $V l_{w}<V l_{t}$. We again relied on a nonparametric test by generating artificial $V l_{w}$ conforming to the null hypothesis (Ho) that $V l_{w}=V l_{t}$ by permuting $h_{i}$ or $v_{i}$ values among populations, independently for each species (999 permutations).

Regression analyses, nonparametric and Mantel tests were performed using the $\mathrm{R}$ statistical software using the vegan package (Oksanen et al. 2011).

\section{Results}

Genetic polymorphism and spatial genetic structure of each species

The number of haplotypes per species varied between six and 24 (list of GenBank accession numbers available in Table S2, Supporting information). Overall diversity values, estimated by $h_{T}$ and $v_{T}$, were higher for S. globulifera and A. kamerunensis (over 0.90), slightly lower for S. zenkeri, A.lepidophyllus and G. suaveolens (between 0.80 and 0.85 ) and much lower for E. suaveolens, S. trimera and M. excelsa (between 0.52 and 0.63) (Table 2).

Afrostyrax kamerunensis displayed highly divergent haplotypes, and almost all sampled populations hosted a single haplotype. The most divergent regions were localized in southwest Cameroon (haplotype 21) and in

Table 2 Numbers of individuals and populations sampled, number of haplotypes and diversity and differentiation statistics for the eight species. Overall diversity (pooled individuals) taking into account $\left(v_{T}\right)$ or ignoring $\left(h_{T}\right)$ genetic distance between haplotypes. Differentiation statistics $G_{\mathrm{ST}}$ and $N_{\mathrm{ST}}$ (based on populations with at least three individuals) and results of permutation tests $N_{\mathrm{ST}}>G_{\mathrm{ST}}$. NS: the test is not significant

\begin{tabular}{|c|c|c|c|c|c|c|c|c|}
\hline & $\begin{array}{l}\text { Number of } \\
\text { individuals }\end{array}$ & $\begin{array}{l}\text { Number of populations } \\
\text { (min-max number } \\
\text { of individuals) }\end{array}$ & $\begin{array}{l}\text { Number of } \\
\text { haplotypes }\end{array}$ & $h_{T}$ & $v_{T}$ & $G_{\mathrm{ST}}$ & $N_{\mathrm{ST}}$ & $P$-value \\
\hline A. kamerunensis & 56 & $10(1-12)$ & 8 & 0.91 & 0.90 & 0.80 & 0.86 & NS \\
\hline A. lepidophyllus & 175 & $29(1-20)$ & 12 & 0.82 & 0.83 & 0.75 & 0.79 & NS \\
\hline E. suaveolens & 153 & $23(1-26)$ & 15 & 0.63 & 0.54 & 0.41 & 0.45 & NS \\
\hline G. suaveolens & 267 & $37(1-24)$ & 15 & 0.80 & 0.82 & 0.61 & 0.66 & NS \\
\hline M. excels & 127 & $19(1-25)$ & 6 & 0.53 & 0.52 & 0.44 & 0.40 & NS \\
\hline S. trimera & 252 & $23(1-24)$ & 6 & 0.63 & 0.61 & 0.61 & 0.63 & NS \\
\hline S. zenkeri & 178 & $25(1-18)$ & 17 & 0.85 & 0.81 & 0.84 & 0.95 & $<0.001$ \\
\hline S. globulifera & 66 & $19(1-13)$ & 24 & 0.97 & 0.98 & 0.65 & 0.79 & $<0.005$ \\
\hline
\end{tabular}


central Gabon (haplotype 12) (Fig. S1, Supporting information). Afrostyrax lepidophyllus was characterized by a group of closely related haplotypes among which two (H2 and H7) were widely distributed in Gabon, eastern Cameroon, Central African Republic (CAR) and Equatorial Guinea (Fig. S3, Supporting information). Western Cameroon was by contrast characterized by two divergent haplotypes (H1 and H16), which were unexpectedly related to $\mathrm{H} 9$ found in CAR, $1000 \mathrm{~km}$ to the East (Fig. S3, Supporting information). Scorodophleus zenkeri displayed a significant phylogeographical signal (Table 2). The most striking feature of this species was the numerous highly divergent and unrelated haplotypes found in southwestern populations of Gabon (Fig. S2, Supporting information).

The spatial genetic structures of G. suaveolens, E. suaveolens, S. santiria and M. excelsa have already been discussed in previous publications (Dainou et al. 2010; Dauby et al. 2010; Duminil et al. 2010; Koffi et al. 2011) and are presented in Figs S4, S5, S6 and S7 (Supporting information), including new data for G. suaveolens and E. suaveolens. Each of these species presented two common and widespread haplotypes, plus a set of localized haplotypes, as in the case of A. lepidophyllus. The two widespread haplotypes had largely overlapping distributions, although their respective centroids were distant by c. $300 \mathrm{~km}$ in G. suaveolens and by c. $100 \mathrm{~km}$ in S. trimera along a north-south axis (Figs S4 and S6, Supporting information). Localized haplotypes were found over the whole ACA in G. suaveolens (but the highly divergent haplotypes H4 and H6 were found only in southwestern Cameroon) and in E. suaveolens (but they were more numerous in Gabon than in Cameroon), while in S.trimera, they were only found in southwestern Cameroon. The four localized haplotypes of M. excelsa were found in eastern ACA (Fig. S7, Supporting information). The spatial genetic structure of S. globulifera has already been described in Budde et al.
(2013), but for a different marker (psbA-trnH). The level of polymorphism and structure were similar for both markers with almost every population hosting one to three localized haplotypes and no widespread haplotypes (Fig. S8, Supporting information, see also Heuertz et al. 2014).

\section{Congruence of genetic divergence patterns among species}

Only results based on $S^{\prime}{ }_{k i j}$ are presented because divergence patterns were broadly similar for $S_{k i j}$ (see Fig. S9, Supporting information). The observed variance of standardized divergence values within pairs of localities, $V p_{w}=0.81$, was significantly lower than the overall variance, $V p_{t}=1.14(P$-value $<0.0001)$, indicating that species tend to share congruent patterns of genetic divergence. Mantel tests (Table 3) revealed that three species (A.lepidophyllus, G. suaveolens and S. trimera) displayed significantly congruent patterns, which also tended to be congruent with the ones displayed by M. excelsa and S. globulifera, although the limited numbers of shared localities limited the power of Mantel tests (only significant between S. globulifera and A. lepidophyllus). In addition, partial congruence with this group of five species was observed for S. zenkeri (congruent with S. trimera) and E. suaveolens (congruent with M. excelsa). By contrast, the divergence pattern of A. kamerunensis did not reveal any congruence with other species.

The genetic distinctiveness of each locality for each species is presented in Fig. 2. This map shows that northwest localities (western Cameroon) and one locality in southern Gabon displayed above-average levels of population distinctiveness for most species, while northeast localities (eastern Cameroon, CAR and northeastern Gabon) generally displayed low levels of genetic distinctiveness for most species. Southern

Table 3 Lower diagonal: congruence between pairwise standardized genetic divergence $\left(S^{\prime}{ }_{k i j}\right)$ across localities for pairs of species (values correspond to Pearson's correlation coefficient; asterisks indicate a $P$-value $<0.05$ in Mantel tests). Upper diagonal: number of shared localities where at least three individuals per species have been sampled. Nc: not computed because there were not enough shared localities

\begin{tabular}{llllllrrr}
\hline & A. kamerunensis & A. lepidophyllus & E. suaveolens & G. suaveolens & M. excelsa & S. trimera & S. zenkeri & S. globulifera \\
\hline A. kamerunensis & & 4 & 2 & 5 & 0 & 4 & 4 & 2 \\
A. lepidophyllus & -0.35 & & 9 & 17 & 6 & 13 & 16 & 4 \\
E. suaveolens & $\mathrm{Nc}$ & -0.23 & & 11 & 7 & 9 & 7 & 3 \\
G. suaveolens & 0.04 & $\mathbf{0 . 5 5 ^ { * }}$ & -0.07 & & 6 & 15 & 19 & 7 \\
M. excelsa & $\mathrm{Nc}$ & 0.09 & $\mathbf{0 . 7 9 ^ { * }}$ & 0.88 & & 4 & 3 & 3 \\
S. trimera & 0.05 & $\mathbf{0 . 7 1 ^ { * }}$ & -0.38 & $\mathbf{0 . 6 5}$ & 0.70 & & 11 & 6 \\
S. zenkeri & -0.13 & 0.16 & 0.24 & 0.27 & $\mathrm{Nc}$ & $\mathbf{0 . 4 1}$ & & 4 \\
S. globulifera & $\mathrm{Nc}$ & $\mathbf{0 . 7 7 ^ { * }}$ & $\mathrm{Nc}$ & 0.31 & $\mathrm{Nc}$ & 0.36 & -0.70 & \\
\hline
\end{tabular}




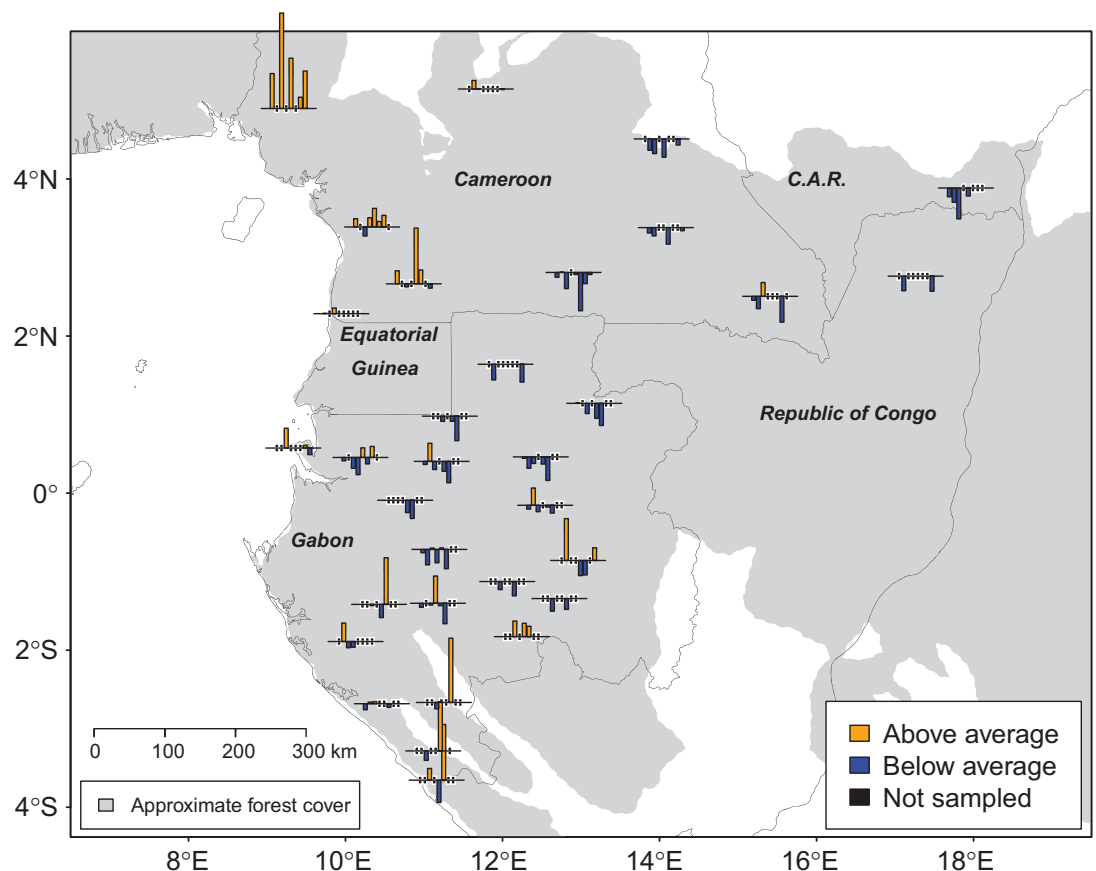

Fig. 2 Genetic distinctiveness of each locality for each species (for localities with at least two species sampled) in Atlantic Central Africa. Distinctiveness above or below average is based on standardized pairwise genetic divergence $\left(S_{k i j}^{\prime}\right.$ computed for each species) among populations (see Materials and methods). Each barplot represents distinctiveness values, respectively, from left to right for the tree species Santiria trimera, Erythrophleum suaveolens, Greenwayodendron suaveolens, Afrostyrax kamerunensis, Afrostyrax lepidophyllus, Scorodophloeus zenkeri, Symphonia globulifera and Milicia excelsa.

localities (central and southwestern Gabon), by contrast, displayed mixed levels of genetic distinctiveness, and hence little congruence among species. Half of the northern populations (i.e. from Cameroon, CAR and northeastern Gabon) displayed congruent divergence patterns (for either low or high levels) compared with less than a quarter for southern populations (i.e. in the remaining area of Gabon). We thus tested whether pairs of populations tended to be similarly differentiated among species separately for northern and southern localities. The northern localities displayed highly significant congruent patterns of divergence among populations $\left(V p_{w}=0.82\right.$ compared to $V p_{t}=1.63$; $P$-value $<0.0001)$. By contrast, no congruence signal was detected in the southern localities $\left(V p_{w}=0.90\right.$ compared to $V p_{t}=0.72$ ).

A synthetic map of average genetic distinctiveness of each locality and standardized divergence between neighbouring localities is proposed (Fig. 3). Most localities in western Cameroon and southwestern Gabon displayed high levels of average genetic distinctiveness and high divergence between neighbouring localities. However, in southwestern Gabon (Fig. 2), this pattern was not similar among species and mostly driven by one of them (S. zenkeri). The northeast region (eastern Cameroon, CAR and northeastern Gabon) was characterized by the low average genetic distinctiveness of its populations, congruent among species (Fig. 2). Another interesting feature of this region was the shared high divergence with western Cameroon localities and, by contrast, the low divergence with Gabonese localities (Fig. 3).

\section{Congruence of genetic diversity patterns among species}

The proportion of populations hosting only one haplotype ranged from $15 \%$ (G. suaveolens) to $78 \%$ (S. globulifera). Population-level diversity indices were not correlated among species within localities: mean variance among species for each locality $V l_{w}=0.079$, while the total variance $V l_{t}=0.072$ for the $v_{i}$ index (the results were similar for $h_{i}$ ).

\section{Discussion}

In this study, phylogeographical patterns of the plastid genome of eight tree species were compared in Atlantic Central Africa. Only two species displayed a significant phylogeographical signal, suggesting that divergence patterns are not very deep in time compared to the (unknown) mutation rates of the plastid DNA regions studied. Although genetic diversities within localities were not correlated among species sampled in the same locations, standardized pairwise genetic divergence among populations displayed congruent patterns. More specifically, populations displaying higher or lower genetic distinctiveness compared to other populations tend to co-occur in similar areas, a pattern that originated mostly from the congruence observed among five of the eight species, and appeared much stronger in the northern part (Cameroon, CAR and northeast Gabon) compared to the southern part (remaining area of Gabon).

The phylogeographical patterns were characterized using chloroplast sequences. As already stated, being 


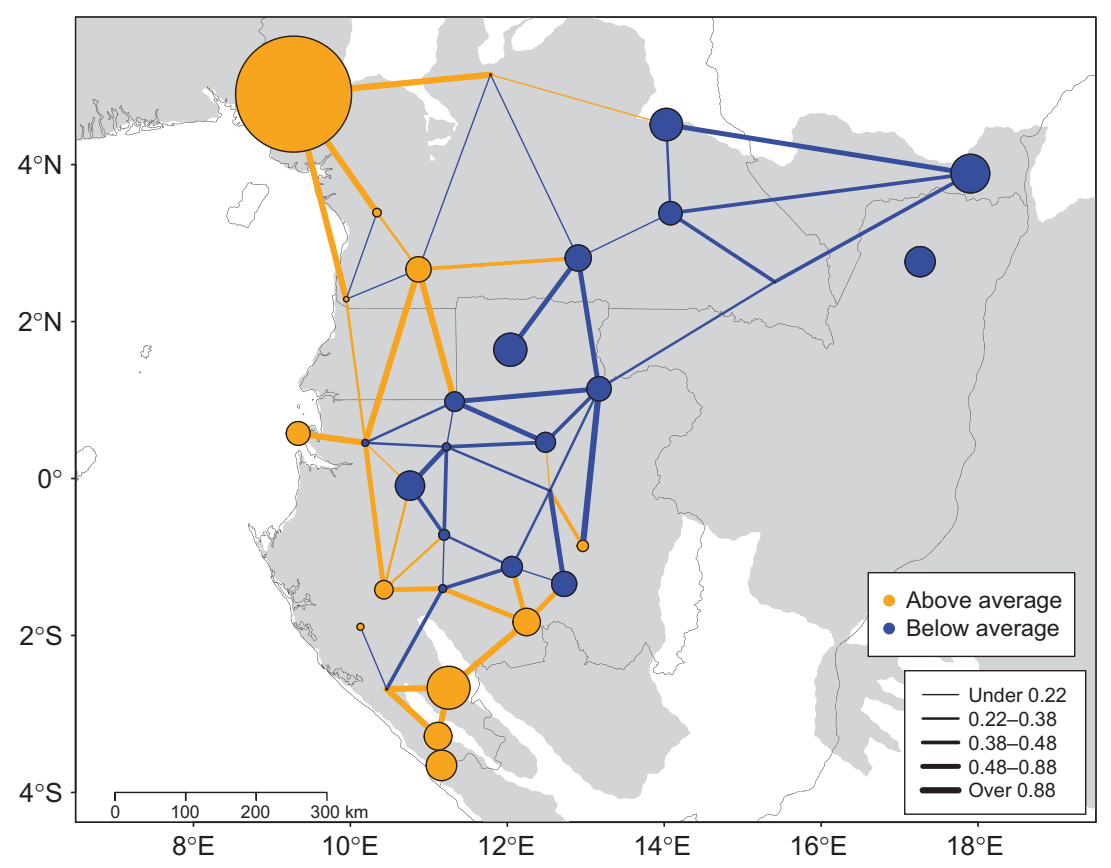

Fig. 3 Genetic distinctiveness of each locality (charts) and standardized divergence between neighbouring localities (lines) averaged over the eight studied tree species in Atlantic Central Africa. Distinctiveness/divergence above (positive values) or below (negative values) average is based on a matrix of multiplespecies pairwise comparison between localities $\left(S^{\prime}{ }_{. i j}\right)$. Chart size and line widths are proportional to, respectively, the mean genetic distinctiveness and the mean standardized divergence. Mean standardized divergence between neighbouring localities is shown only if at least two species are shared. generally maternally inherited, pDNA markers may be particularly informative for inferring populations' history shaped by seed colonization independently of long-distance pollen flow (Petit et al. 2003). One limitation, however, of relying only on pDNA is their nonrecombinant nature. A given spatial genetic structure inferred by pDNA thus reflects one instance of molecular evolution under a given demographical history whereas simulations have shown that a given demographical history may lead to a wide range of genetic patterns because of the influence of stochastic processes (Carstens et al. 2005; Kuo \& Avise 2005). Therefore, the patterns should ideally be confirmed using additional unlinked molecular markers (e.g. nuclear markers). Nevertheless, despite the limited power of our analysis, we did detect an overall significant congruence of phylogeographical patterns among species.

\section{An emerging pattern of genetic distinctiveness in the Lower Guinea phytogeographical region}

Relying on the patterns described here, the study area can be broadly divided into three large regions: (i) the northwest region (western Cameroon), characterized by its high level of mean genetic distinctiveness, congruent across species (Fig. 2) and its strong divergence with adjacent populations from Gabon and from the eastern regions (Fig. 3). Indeed, all species but $M$. excelsa sampled in western Cameroon (six species, as E. suaveolens does not occur there) display endemic and sometimes highly divergent haplotypes in this area. (ii) The northeast region (eastern Cameroon, CAR and northeastern Gabon) is characterized by its congruent low level of genetic distinctiveness (Fig. 2). Indeed, its populations (for seven species as A. kamerunensis does not occur there) are mostly composed of widespread haplotypes, often ranging from central Gabon to CAR and northern Congo. (iii) Finally, the southern region (central and south Gabon) harbours populations characterized by their overall low congruence in local genetic distinctiveness patterns among species (Fig. 2). For example, populations of southern Gabon display several endemic haplotypes in S. zenkeri and A. lepidophyllus, but none in S. trimera (Fig. S6, Supporting information). The distinction between western Cameroon and the remaining ACA is consistent with phylogeographical patterns based on nuclear microsatellites (Hardy et al. 2013).

\section{Multispecies phylogeographical patterns show partial agreement with putative refugia proposed in the literature}

Several maps of putative refugia have been proposed in the literature (e.g. Maley 1987; Hamilton \& Taylor 1991; Senterre 2005), but they are not necessarily congruent and lack fine-scale spatial resolution. It has been hypothesized that those refugia were mostly localized in hilly and mountainous regions where topographic heterogeneity would have maintained sufficiently humid habitats for rainforest vegetation during the most arid phases of the Pleistocene (Maley 1996; Sosef 1996). This hypothesis has been supported by the fact 
that these regions harbour high levels of endemism (Hamilton \& Taylor 1991; Robbrecht 1996; Sosef 1996; Droissart 2009). Here, we made no assumption on the putative localization of forest refugia but rather tried to infer their position as well as recolonized areas based on our data only. Patterns of genetic distinctiveness partly support the refuge hypothesis as three regions with high and mostly congruent levels of genetic distinctiveness actually correspond to putative refugia: the Cameroonian volcanic line, the Ngovayang massif and the South of the Massif du Chaillu (Figs 1 and 3). On the contrary, other mountainous regions that have also been proposed as putative refugia in the literature do not display any trend of high and congruent genetic distinctiveness (for example, Monts de Cristal, Belinga or Monts Doudou, see Fig. 1).

\section{Historical interpretation of genetic divergence patterns}

The most divergent populations in western Cameroon are localized north and south of the Sanaga River (Fig. 3, respectively, the Cameroonian volcanic line and the Ngovayang massif, see Fig. 1), which have been defined by several authors as two distinct areas of plant species endemism (Cheek et al. 2001; Droissart et al. 2011). Among the eight studied species, three were poorly sampled or not sampled at all north of the Sanaga River, marking the limit of their northern range. It is unlikely that the Sanaga River is a physical barrier in itself for plant dispersal. Droissart et al. (2011) instead proposed that the forest along the Sanaga River was strongly fragmented during the drier periods of the Quaternary while forest refugia would have occurred in adjacent mountainous areas (the Cameroonian volcanic line in the north and the Ngovayang massif in the south, see Fig. 1). The climatic history of this region has been relatively well documented for the last 24000 years based on two fossil pollen cores (ReynaudFarrera et al. 1996; Maley \& Brenac 1998). Overall, these palaeoclimatic data showed that the forest cover never completely disappeared but varied considerably in its composition, that is, in the relative importance of evergreen, secondary and mountainous indicator taxa (Bonnefille 2007). Hence, the forest cover of this region may have been relatively spared by the last climatic deteriorations, but populations of mature forest species probably diminished in size and/or became fragmented. Accordingly, in a comparative study of the genetic diversity of an ant-tree species and its two associated ant species, Leotard et al. (2009) found congruent genetic signatures of a recent southward expansion in southwestern Cameroon, highlighting population dynamics in this area perhaps linked to past climatic changes.
The genetic discontinuity between the regions north and south of the Sanaga River described in the present study (Figs 2 and 3) supports the scenario of past fragmentation into at least two main refugia located approximately north and south of the Sanaga River. Interestingly, while a discontinuity has been described both for plant diversity patterns (Droissart et al. 2011 for flora belonging to Rubiaceae and Orchidaceae) and for the pDNA diversity pattern (this study), the synthesis of Hardy et al. (2013), mostly based on microsatellites, did not reveal any genetic split in this specific area. In fact, the impact of a relatively ancient historical event may still be noticeable with plastid sequences but not with nuclear microsatellites where long-distance pollen dispersal and/or homoplasious mutations may have erased the signature of past population fragmentation. The shared high level of genetic divergence between western Cameroon and Gabon is, by contrast, in agreement with microsatellite data (Debout et al. 2011; Hardy et al. 2013). A possible explanation for the existence of both congruent and incongruent patterns between microsatellite and pDNA sequence data is that historical events at the origin of such patterns (forest cover resilience during past climatic fluctuations) could vary in their strength and time frame. Depending on these two parameters, historical climatic change events may leave signatures that today can be observed at either the species or within-species level. Regarding the latter, the signal will depend on marker inheritance and mutation rate. However, an explicit characterization of the spatial concordance between gene pools (defined by microsatellites) and patterns of pDNA diversity as well as species diversity still has to be conducted.

Forests from the northeast region (eastern Cameroon, northeastern Gabon, CAR and northern Congo) are mostly semi-deciduous and characterized by a lower mean annual rainfall and elevation heterogeneity compared with the regions along the Atlantic coast. They have never been proposed as putative refugia. A peculiar feature of present-day forest composition in many areas of these regions is the abundance of lightdemanding tree species in the canopy (Brncic et al. 2007) and the scattered presence of open-forest formations dominated by Marantaceae (Harris 2002; Gillet \& Doucet 2012), which have been related to past human activities and/or drier climatic periods of the Holocene (Maley 2001; Brncic et al. 2009). In these regions, the concordant patterns of low genetic distinctiveness support a scenario of severe reduction in rainforest tree populations followed by a recolonization from possibly one or two main sources. Current data do not allow identifying these sources. They may be local (e.g. micro-refugia in the form of gallery forests or scattered forest remnants) or external (e.g. recolonization from 
macro-refugia in western Cameroon, Gabon or the Congo basin). For several species (e.g. S. zenkeri, A. lepidophyllus), the absence of shared haplotypes between western and eastern Cameroon indicates that recolonization could not have started from a west Cameroonian refugium. In conclusion, patterns of genetic distinctiveness in the northern ACA are in agreement with a scenario of past forest fragmentation with refugium areas in western Cameroon and recolonized areas in the east.

Within Gabon, the lack of congruence among species could be explained if the forest cover had not been reduced dramatically in the past, leading to idiosyncratic demographical histories of tree species. This scenario is in agreement with Kingdon (1980) who proposed a large refugium covering all Gabon based on the distribution of primates.

\section{Influence of species ecological attributes on the congruence of phylogeographical patterns}

Patterns of congruence among pDNA-based phylogeographical patterns can be influenced by species life history traits in at least two ways. First, we may expect weaker signature of past events of fragmentation and recolonization for species with high dispersal capacities. High migration rates may indeed erase historical imprints on spatial genetic structure and/or decrease the influence of founder events. However, the level of congruence and the mode of dispersal do not seem to be related for the eight studied species. For example, Milicia excelsa, whose phylogeographical pattern tends to be congruent with other species (Table 3), is likely to have the most efficient mode of dispersal among the eight species: indirect estimates of gene flow suggested that seeds often disperse over several kilometres by bats (Daïnou et al. 2010). By contrast, the seed dispersal capacity of Erythropleum suaveolens is estimated to be on average $200 \mathrm{~m}$ (Hardy OJ, unpublished results) while its phylogeographical pattern is poorly correlated to the others (Table 3). Second, the degree of shared history among species, and the resulting level of congruence among phylogeographical patterns, could actually differ between sets of species with similar life history traits and habitat affinities (Hardy et al. 2013). This scenario is well illustrated in European forests where boreal and temperate tree species display distinct spatial patterns of genetic diversity (Petit et al. 2003). In Central Africa, we may, for example, expect different patterns for species typical of moist semi-deciduous forest and for species typical of evergreen wet forest. Among the eight species studied, two are typical of semi-deciduous forests (M. excelsa and E. suaveolens), while the six others are more typical of wet forests. Interestingly, the distinctiveness pattern of E. suaveolens is only significant with the one of M. excelsa. However, currently available data sets of spatial genetic diversity for Central African trees are still insufficient for detecting relationships between species ecological attributes and phylogeographical patterns. This question is further hampered by our limited knowledge of life history traits, including dispersal capacity, and habitat affinities for many tropical tree species. Our understanding of the impacts of past climatic fluctuations on species ranges and forest cover would therefore benefit from phylogeographical studies extending the ecological focus to dry forest and savannahs.

\section{Alternative interpretation based on present-day processes}

Apart from historical interpretations, phylogeographical patterns can alternatively be explained by permanent barriers to gene flow. For example, rivers explain well the structure of genetic diversity in mammals (Telfer et al. 2003; Anthony et al. 2007), and the Andes are important in structuring phylogeographical patterns of numerous Neotropical organisms (Turchetto-Zolet et al. 2013). Rivers are unlikely to be efficient barriers to gene flow for plants, and there is no equivalent of the Andean cordillera in ACA, but mountainous areas and savannahs might disrupt gene flow among populations, especially for species with low dispersal ability and/or restricted to naturally fragmented habitats. For example, highly divergent populations were observed for S. zenkeri in southwestern Gabon, a region characterized by a highly heterogeneous landscape (elevation variability and savannah-forest mosaics, Figs 1 and 3). S. zenkeri is a rare species in the littoral region whereas it is much more frequent inland (dominant species in mature forests). This species also displays a ballochorous dispersal syndrome, that is, a restricted seed dispersal mechanism. Hence, the high divergence of $S$. zenkeri populations in southwestern Gabon could be explained by a lack of connectivity and/or low effective population sizes compared with inland populations.

\section{Conclusion}

Disjunctions and similarities among phylogeographical patterns of rainforest species were demonstrated, suggesting a partially shared history driven by forest range dynamics during the Pleistocene. Localities characterized by a shared pattern of high distinctiveness are partly consistent with Quaternary forest refugia postulated from palaeoecological and species distribution data (e.g. Maley 1987; Sosef 1996). We therefore highlight the potential congruence between phylogeographical 
and species endemism and diversity patterns, at least in northern parts of ACA, supporting the hypothesis that historical processes repeatedly and similarly influenced the distribution of biodiversity in the region. However, this conclusion is still premature as a comparison between interspecific and intraspecific patterns of diversity has not yet been conducted. The synthesized patterns of genetic distinctiveness provide the first comprehensive framework in central African forests for testing such historical influence on present-day species distribution and assembly.

\section{Acknowledgements}

This study was made possible by the support from the United States Agency for International Development (USAID) and the Wildlife Conservation Society under a USAID co-operative agreement (623-A-00-06-00067-00). Fieldwork done by GD was financed by the Communauté Française de Belgique, the Belgian Fund for Scientific Research (F.R.S.-FNRS) and the Fond Cassel. Sampling in Gabon was conducted with the support of the Herbier National $d u$ Gabon (IPHAMETRA) under permission from CENAREST. Laboratory work was financed by F.R.S.FNRS (grants FRFC 2.4577.10 and MIS F.4.519.10.F) and by the C3A project financed by the French ANR (Agence Nationale de la Recherche) under the ANR-BIODIV programme. GD was funded by the Belgian Fund for Research Training in Industry and Agriculture (FRIA) and the F.R.S.-FNRS, and MH acknowledges a Ramón y Cajal Fellowship from the Spanish Ministry of Science and Innovation and a Marie Curie IntraEuropean Fellowship.

\section{References}

Anthony NM, Johnson-Bawe M, Jeffery K et al. (2007) The role of Pleistocene refugia and rivers in shaping gorilla genetic diversity in central Africa. Proceedings of the National Academy of Sciences of the United States of America, 104, 20432-20436.

Avise JC (1992) Molecular population structure and the biogeographic history of a regional fauna: a case history with lessons for conservation biology. Oikos, 63, 62-76.

Bandelt HJ, Forster P, Rohl A (1999) Median-joining networks for inferring intraspecific phylogenies. Molecular Biology and Evolution, 16, 37-48.

Bermingham E, Moritz C (1998) Comparative phylogeography: concepts and applications. Molecular Ecology, 7, 367-369.

Bonnefille R (2007) Rainforest responses to past climatic tropical Africa. In: Tropical Rainforest Responses to Climatic Change (eds Bush MB, Flenley JR, Bonnefille R), pp. 117-170. Springer, Berlin Heidelberg.

Brncic TM, Willis KJ, Harris DJ, Washington R (2007) Culture or climate? The relative influences of past processes on the composition of the lowland Congo rainforest. Philosophical Transactions of the Royal Society B-Biological Sciences, 362, 229 242.

Brncic TM, Willis KJ, Harris DJ, Telfer MW, Bailey RM (2009) Fire and climate change impacts on lowland forest composition in northern Congo during the last 2580 years from palaeoecological analyses of a seasonally flooded swamp. The Holocene, 19, 79-89.

Budde K, González-Martínez SC, Hardy OJ, Heuertz M (2013) The ancient tropical rainforest tree Symphonia globulifera L. f. (Clusiaceae) was not restricted to postulated Pleistocene refugia in Atlantic Equatorial Africa. Heredity, 111, 66-76.

Bush MB, Oliveira PED (2006) The rise and fall of the refugial hypothesis of Amazonian speciation: a paleoecological perspective. Biota Neotropica, 6, 1-17.

Carstens BC, Degenhardt JD, Stevenson AL, Sullivan J (2005) Accounting for coalescent stochasticity in testing phylogeographical hypotheses: modelling Pleistocene population structure in the Idaho giant salamander Dicamptodon aterrimus. Molecular Ecology, 14, 255-265.

Cheek M, Mackinder B, Gosline G, Onana JM, Achoundong G (2001) The phytogeography and flora of western Cameroon and the Cross river-Sanaga River interval. Systematics and Geography of Plants, 71, 1097-1100.

Daïnou K, Bizoux J-P, Doucet J-L et al. (2010) Forest refugia revisited: nSSRs and cpDNA sequences support historical isolation in a wide-spread African tree with high colonization capacity, Milicia excelsa (Moraceae). Molecular Ecology, 19, 4462-4477.

Dauby G, Duminil J, Heuertz M, Hardy O (2010) Chloroplast DNA polymorphism and phylogeography of a Central African tree species widespread in mature rainforests: Greenwayodendron suaveolens (Annonaceae). Tropical Plant Biology, 3, 4-13.

Debout GDG, Doucet JL, Hardy OJ (2011) Population history and gene dispersal inferred from spatial genetic structure of a Central African timber tree, Distemonanthus benthamianus (Caesalpinioideae). Heredity, 106, 88-99.

Dexter KG, Terborgh JW, Cunningham CW (2012) Historical effects on beta diversity and community assembly in Amazonian trees. Proceedings of the National Academy of Sciences, 109, 7787-7792.

Doyle JJ, Doyle JL (1987) A rapid isolation procedure from small quantities of fresh leaf tissues. Phytochemical Bulletin, 19, $11-15$

Droissart V (2009) Etude taxonomique et biogéographique des plantes endémiques d'Afrique centrale atlantique: le cas des Orchidaceae PhD thesis, Université Libre de Bruxelles, Belgique.

Droissart V, Sonké B, Hardy O et al. (2011) Do plant families with contrasting functional traits show similar patterns of endemism? A case study with Central African Orchidaceae and Rubiaceae. Biodiversity and Conservation, 20, 1507-1531.

Duminil J, Heuertz M, Doucet JL et al. (2010) CpDNA-based species identification and phylogeography: application to African tropical tree species. Molecular Ecology, 19, 54695483.

Fjeldså J, Lovett JC (1997) Geographical patterns of old and young species in African forest biota: the significance of specific montane areas as evolutionary centres. Biodiversity and Conservation, 6, 325-346.

Gillet J-F, Doucet J-L (2012) A commented checklist of woody plants in the Northern Republic of Congo. Plant Ecology and Evolution, 145, 258-271.

Haffer J (1969) Speciation in Amazonian forest birds. Science, 165, 131-137. 
Hamilton AC, Taylor D (1991) History of climate and forests in tropical Africa during the last 8 million years. Climatic Change, 19, 65-78.

Hardy OJ, Vekemans X (2002) SPAGEDi: a versatile computer program to analyse spatial genetic structure at the individual or population levels. Molecular Ecology Notes, 2, 618-620.

Hardy OJ, Born C, Budde K et al. (2013) Comparative phylogeography of African rainforest trees: a review of genetic signatures of vegetation history in the Guineo-Congolian domain. Comptes rendus Geoscience, 345, 284-296.

Harris DJ(2002) The vascular plants of the Dzanga-Sangha reserve, Central African Republic. In: Scripta Botanica Belgica (ed. Robbrecht E), pp. 1-274. National Botanic Garden of Belgium, Meise.

Heuertz M, Duminil J, Dauby G, Savolainen V, Hardy OJ (2014) Comparative phylogeography in rainforest trees from Lower Guinea, Africa. PLoS ONE, 9, e84307.

Hewitt G (2000) The genetic legacy of the Quaternary ice ages. Nature, 405, 907-913.

Hoorn C, Wesselingh FP, ter Steege H et al. (2011) Amazonia through time: Andean uplift, climate change, landscape evolution, and biodiversity. Science, 330, 927-931.

Kembel SW, Cowan PD, Helmus MR et al. (2010) Picante: R tools for integrating phylogenies and ecology. Bioinformatics, 26, 1463-1464

Kidd D, Liu X (2008) geophylobuilder 1.0: an arcgis extension for creating "geophylogenies". Molecular Ecology Resources, 8, 88-91.

Kingdon JS (1980) The role of visual signals and face patterns in African forest monkeys (guenons) of the genus Cercopithecus. The Transactions of the Zoological Society of London, 35, 425-475

Knapp S, Mallet J (2003) Refuting refugia? Science, 300, 71-72.

Koffi KG, Heuertz M, Doumenge C et al. (2010) A combined analysis of morphological traits, chloroplast and nuclear DNA sequences within Santiria trimera (Burseraceae) suggests several species following the biological species concept. Plant Ecology and Evolution, 143, 160-169.

Koffi KG, Hardy OJ, Doumenge C, Cruaud C, Heuertz M (2011) Diversity gradients and phylogeographic patterns in Santiria trimera (Burseraceae), a widespread African tree typical of mature rainforests. American Journal of Botany, 98, 254264.

Kuo C-H, Avise J (2005) Phylogeographic breaks in low-dispersal species: the emergence of concordance across gene trees. Genetica, 124, 179-186.

Leal ME (2004) The African rain forest during the last glacial maximum, an archipelago of forests in a sea of grass PhD thesis, Wageningen University.

Lebamba JL, Vincens A, Jolly D et al. (2009) Modern pollen rain in savanna and forest ecosystems of Gabon and Cameroon, Central Atlantic Africa. Review of Palaeobotany and Palynology, 153, 34-45.

Leotard G, Debout G, Dalecky A et al. (2009) Range expansion drives dispersal evolution in an equatorial three-species symbiosis. PLOS ONE, 4, e5377.

Linder HP, de Klerk HM, Born J et al. (2012) The partitioning of Africa: statistically defined biogeographical regions in sub-Saharan Africa. Journal of Biogeography, 39, 1189-1205.

Maley J (1987) Fragmentation de la forêt dense humide africaine et extension des biotopes montagnards au Quaternaire récent: nouvelles données polliniques et chronologiques. Implications paléoclimatiques et biogéographiques. Palaeoecology of Africa, 18, 307-334.

Maley J (1996) The African rain forest - main characteristics of changes in vegetation and climate from the upper cretaceous to the quaternary. Proceedings of the Royal Society of Edinburgh, 104B, 31-73.

Maley J (2001) The catastrophic destruction of Central African rain forests occurring about 2500 years ago still exerts a major influence on the present distribution of vegetation formations. Systematics and Geography of Plants, 71, 777-796.

Maley J, Brenac P (1998) Vegetation dynamics, palaeoenvironments and climatic changes in the forests of western Cameroon during the last 28000 years B.P. Review of Palaeobotany and Palynology, 99, 157-187.

Mayr E, O'Hara RJ (1986) The biogeographic evidence supporting the Pleistocene forest refuge hypothesis. Evolution, 40, $55-67$.

Oksanen J, Blanchet FG, Kindt R et al. (2011) vegan: Community Ecology Package. $\mathrm{R}$ package version 1.17-10. http:// CRAN.R-project.org $/$ package=vegan .

Petit RJ, Aguinagalde I, de Beaulieu JL et al. (2003) Glacial refugia: hotspots but not melting pots of genetic diversity. Science, 300, 1563-1565.

Plana V (2004) Mechanisms and tempo of evolution in the African Guineo-Congolian rainforest. Philosophical Transactions of the Royal Society of London Series B-Biological Sciences, 359, 1585-1594.

Plana V, Gascoigne A, Forrest LL, Harris D, Pennington RT (2004) Pleistocene and pre-pleistocene Begonia speciation in Africa. Molecular Phylogenetics and Evolution, 31, 449-461.

Pons O, Petit RJ (1996) Measuring and testing genetic differentiation with ordered versus unordered alleles. Genetics, 144, 1237-1245.

R Development Core Team (2011) A language and environment for statistical computing, Vienna, Austria.

Reynaud-Farrera I, Maley J, Wirrmann D (1996) Végétation et climat dans les forêts du sud-ouest Cameroun depuis 4770 ans BP: analyse pollinique des sédiments du lac Ossa. Comptes Rendus de l'Académie des Sciences de Paris.Série 2a: Sciences de la Terre et des Planètes, pp. 749-755.

Ricklefs RE (2004) A comprehensive framework for global patterns in biodiversity. Ecology Letters, 7, 1-15.

Robbrecht E (1996) Geography of African Rubiaceae with reference to glacial rain forest refuges. In: The biodiversity of African Plants: Proceedings XIVth AETFAT Congress (eds van der Maesen LJG, van der Burgt XM, van Medenbach de Rooy JM), pp. 564-581. Kluwer Academic Publishers, Netherlands.

Schönswetter P, Stehlik I, Holderegger R, Tribsch A (2005) Molecular evidence for glacial refugia of mountain plants in the European Alps. Molecular Ecology, 14, 3547-3555.

Senterre B (2005) Recherches méthodologiques pour la typologie de la végétation et la phytogéographie des forêts denses d'Afrique tropicale PhD thesis, Université Libre de Bruxelles.

Shaw J, Lickey EB, Beck JT et al. (2005) The tortoise and the hare II: relative utility of 21 noncoding chloroplast DNA sequences for phylogenetic analysis. American Journal of Botany, 92, 142-166.

Sosef M (1996) Begonias and African rain forest refuges: general aspects and recent progress. In: The biodiversity of African 
Plants: Proceedings XIVth AETFAT congress (eds van der Maesen LJG, van der Burgt XM, van Medenbach de Rooy JM), pp. 602-611. Kluwer Academic Publishers, Netherlands.

Taberlet P, Fumagalli L, Wust-Saucy A-G, Cosson J-F (1998) Comparative phylogeography and postglacial colonization routes in Europe. Molecular Ecology, 7, 453-464.

Telfer PT, Souquiere S, Clifford SL et al. (2003) Molecular evidence for deep phylogenetic divergence in Mandrillus sphinx. Molecular Ecology, 12, 2019-2024.

Turchetto-Zolet AC, Pinheiro F, Salgueiro F, Palma-Silva C (2013) Phylogeographical patterns shed light on evolutionary process in South America. Molecular Ecology, 22, 1193-1213.

Zink RM (2002) Methods in comparative phylogeography, and their application to studying evolution in the North American Aridlands. Integrative and Comparative Biology, 42, 953959.

O.H. and G.D. designed research; G.D. performed the analyses; G.D., G.K., J.D. and M.H. contributed to data generation; G.D., G.K., J.D., M.H., O.H. and T.S. collected samples; G.D. and O.H. wrote the paper, and all authors critically revised the manuscript.

\section{Data accessibility}

Sequences have been deposited on GenBank (see Table S2, Supporting information).

Sampling locations and inputs files for analysis: Dryad doi:10.5061/dryad.3tc00 and Table S1 (Supporting information).

\section{Supporting information}

Additional supporting information may be found in the online version of this article.

Table S1 List of localities, coordinates and numbers of individuals sampled for each species

Table S2 Genbank accession number for each markers and species

Fig. S1 Distribution of plastid DNA haplotypes of Afrostyrax kamerunensis.

Fig. S2 Distribution of plastid DNA haplotypes of Scorodophloeus zenkeri.

Fig. S3 Distribution of plastid DNA haplotypes of Afrostyrax lepidophyllus.

Fig. S4 Distribution of plastid DNA haplotypes of Greenwayodendron suaveolens subsp. suaveolens var. suaveolens.

Fig. S5 Distribution of plastid DNA haplotypes of Erythrophleum suaveolens.

Fig. S6 Distribution of plastid DNA haplotypes of Santiria trimera.

Fig. S7 Distribution of plastid DNA haplotypes of Milicia excelsa.

Fig. S8 Distribution of plastid DNA haplotypes of Symphonia globulifera.

Fig. S9 Genetic distinctiveness of each tree species within each locality (for localities with at least 2 species sampled) in Atlantic Central Africa. 